\title{
Sensitivity experiments to sea surface temperatures, sea-ice extent and ice-sheet reconstruction, for the Last Glacial Maximum
}

\author{
G. RAMSTEIN \\ Laboratoire de Modélisation du Climat el de l'Environnement CEN Saclay, Bat. 709, Gif-sur-Yvelle 91191, France
}

\author{
S. Joussaume \\ Laboratoire de Modélisation du Climat et de l'Environnement and LOD TC, C.NRS/Universilé P. ¿ீ M. Curie/ORSTOM, \\ Paris, France
}

\begin{abstract}
For the Last Glacial Maximum, (LGM; $21000 \mathrm{BP}$ ), simulations using atmospheric general-circulation models (AGCMs) are very sensitive to the prescribed boundary conditions. Most of the recent numerical experiments have used the CLIMAP (1981) data set for ice-sheet topography, sea-ice extent and sea surface temperatures (SSTs). To demonstrate the impact of ice-sheet reconstruction on the LGM climate, we performed two simulations: one using CLIMAP (1981) ice-sheet topography, the other using the new reconstruction provided by Peltier. We show that, although the geographical structure of the annually averaged temperature is not modified, there are important seasonal and regional impacts on the temperature distribution. In a second step, to analyze the effects of cooler SSTs and sea-ice extent, we performed a simulation using CLIMAP (1981) for the ice-sheet topography, but with present SSTs. We find that the cooling due to ice sheets for the LGM climate is one-third of the global annually averaged cooling, and that the southward shift of the North Atlantic low in winter is not due to sea-ice extent, but is an orographic effect due to the Laurentide ice sheet. This set of sensitivity experiments allows us also to discriminate between thermal and orographic forcings and to show the impact of the ice-sheet topography and cooler SSTs on the pattern of planetary waves during the LGM climate.
\end{abstract}

\section{INTRODUCTION}

Atmospheric general-circulation models (AGCMs) are important tools for reconstructing past atmospheric circulations and studying the physical mechanisms of climate change. To investigate the role of the different components (or boundary conditions) of the Last Glacial Maximum (LGM) climate, we performed a set of four numerical experiments, using the Laboratoire de Météorologie Dynamique (LMD) AGCM. Many simulations have been done with different AGCMs to quantify the effect of boundary conditions on the global temperature decrease during the LGM. For example, Broccoli and Manabe (1987), using an AGCM coupled with a slab ocean model, emphasized the role of low $\mathrm{CO}_{2}$ partial pressure, especially for the Southern Hemisphere, while Rind (1987) showed the impact of snow feed-back and of the topography of the ice sheets.

Our approach focuses on the role of two major boundary conditions:

1. Sea surface temperatures (SSTs) as given by CLIMAP, McIntyre and Cline, 1981; hereafter called CLIMAP (1981)) in winter and summer for the LGM and modern climates.
2. Ice-sheet reconstructions (ISRs) for which two data sets are available, CLIMAP (1981) and a revised one provided by Peltier (1994).

Some sensitivity experiments with SST and ISR have already been performed. Rind (1987) studied the impact of CLIMAP (1981) LGM SSTs under present climatic conditions, and Rind and Peteet (1985) made a sensitivity experiment uniformly lowering the CLIMAP (1981) LGM SST by $2^{\circ} \mathrm{C}$ to improve the consistency of lowlatitude temperatures deduced from data and from models; but there is still no study of present-climate SST impact on LGM dynamics.

On the other hand, Shinn and Barron (1989) have studied the sensitivity of the LGM climate to extreme continental ice-sheet size and configuration. In their experiment, the differences between maximum and minimum ice sheets are huge in comparison with our simulation; yet some interesting comparisons, especially about the splitting of the polar jet due to the Laurentide ice sheet, can be made. Moreover, the fact that all the modellers involved in the Paleoclimate Modeling Intercomparison Project (personal communication from S. Joussaume and K. Taylor, 1994) will use the new icesheet reconstruction provided by Peltier (1994) reinforces 
interest in whether changing the ISR has an important impact on the LGM climate.

\section{MODEL AND SIMULATION DESGRIPTION}

All the simulations were performed with the LMD version 4 AGCM (Le Treut and Li, 1991) which is a grid-point model. We used the low-resolution version, corresponding to 48 points regularly spaced in longitude and 36 points regularly spaced in sine of latitude. At the equator, the grid spacing is $830 \mathrm{~km}$ of longitude $\times 270 \mathrm{~km}$ of latitude, and at $45^{\circ}$ of latitude it corresponds to $590 \mathrm{~km}$ longitude $\times 530 \mathrm{~km}$ latitude. The model has 11 levels in normalized pressure coordinate $(\sigma)$. The model solves the dynamic and thermodynamic equations, and the continuity equation for mass and water vapour Sadourny and Laval, 1984). The predicted clouds are considered for the radiative-transfer calculations (Le Treut and Laval, 1984). Each experiment includes the full seasonal cycle and lasts 6 years; averages are made over the last 5 years.

The first of the four simulations (EXPl) is the control run which simulates the present climate. The second (EXP2) is a simulation of the LGM using the CLIMAP (1981) data set for SST and ISR. The third (EXP3) is a sensitivity experiment with the ice-sheet topography in which we replaced the CLIMAP (1981) reconstruction by the new reconstruction provided by Peltier (1994); all the other boundary conditions are identical to EXP2. The fourth simulation (EXP4) is a sensitivity experiment with SST in which the CLIMAP (1981) reconstructed SST for the Last Glacial Maximum has been replaced by the present climate SST of the control run, with all the other boundary conditions remaining identical to EXP2 (Table 1).

Comparing EXP3 and EXP2 will give us the sensitivity of the LGM climate to the differences in icesheet reconstruction. Comparing EXP4 and EXP1 which both have the same prescribed SST will give us the impact of the ice-sheet topography. Finally, comparing EXP4 and EXP2, which both have the same CLIMAP (1981) ISR, will give us the SST impact on the LGM climate.

\section{CHANGES IN BOUNDARY CONDITIONS}

\subsection{Ice-sheet reconstruction}

A major difference between present and LGM climate is the huge ice sheets covering northwestern Europe (Fennoscandia) and the northern part of North America
(Laurentide). The shape and size of these ice sheets have an important impact on the atmospheric dynamics over the Northern Hemisphere during the LGM. Denton and Hughes (1981) provided for CLIMAP two reconstructions referenced as MIN and MAX, corresponding to a eustatic sea-level rise of 127 and $163 \mathrm{~m}$, respectively. Peltier (1994) shows that even the MIN reconstruction was excessive, and proposes a new reconstruction based on a gravitationally self-consistent theory of relative sea-level changes which corresponds to a eustatic sea-level rise of $105 \mathrm{~m}$, and to a $55 \%$ reduction of the ice volume in comparison with the CLIMAP MAX reconstruction. Figure $1 \mathrm{a}$ and $\mathrm{b}$ show the change in elevation between the LGM and the present climate for the CLIMAP and Peltier reconstructions. The extent of ice sheets is not very different, but the elevation is $1500 \mathrm{~m}$ higher over Laurentide and about $1000 \mathrm{~m}$ higher over Fennoscandia in the CLIMAP reconstruction. The
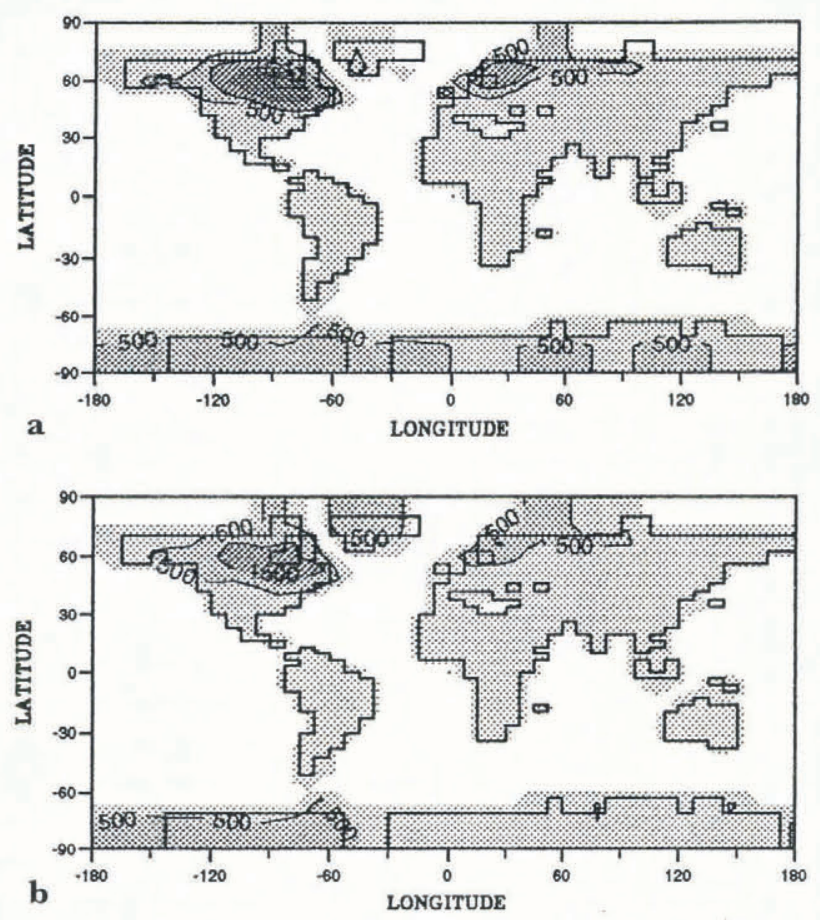

Fig. 1. Differences in elevation (in $\mathrm{m}$ ) between the present (EXPI) and the LGM, using (a) CLIMAP (1981) for LGM ice-sheet topography (EXP2), (b) Peltier (1994) for LGM ice-sheel lopography (EXP3). Dark grey corresponds to elevation differences of more than $2000 \mathrm{~m}$, medium grey to elevation differences of more than $1000 \mathrm{~m}$, light grey to the emerged lands at the LGM. Isolines for 1500 and $500 \mathrm{~m}$ are also drawn.

Table 1. Main parameter differences for the sel of numerical experiments

\begin{tabular}{lcccc}
\hline & $\begin{array}{c}\mathrm{CO}_{2} \\
\mathrm{PPm}\end{array}$ & Insolation & SST data sel & ISR data set \\
& & & & \\
\hline EXP1 control run & 320 & 1950 & Present & Present \\
EXP2-LGM CLIMAP (1981) & 200 & $21 \mathrm{ka} \mathrm{BP}$ & CLIMAP (1981) & CLIMAP (1981) \\
EXP3-LGM Peltier (1994) & 200 & $21 \mathrm{ka} \mathrm{BP}$ & CLIMAP (1981) & Peltier (1994) \\
EXP4-LGM (SST present) & 200 & $21 \mathrm{ka} \mathrm{BP}$ & Present & CLIMAP (1981) \\
& & & &
\end{tabular}


lower sea-level rise in Peltier's reconstruction, compared with CLIMAP, leads to a reduction of the emerged lands. We take this into account and use different sea/land masks for the two simulations.

\subsection{Sea surface temperatures}

Most of the recent simulations of the LGM climate, performed with AGCMs and prescribed SSTs, have used the reconstruction of the sea-ice extent and of the sea surface temperatures, for summer and winter seasons, provided by CLIMAP (1981). These data are still controversial, e.g. in the tropical area (Webster and Streten, 1978; Rind and Peteet, 1985), but no global revision of LGM SST is yet available, and we use CLIMAP (1981) to reconstruct daily evolution of SST and sea-ice extent.

The SST differences between the LGM and the present climate are about $-4^{\circ}$ to $-6^{\circ} \mathrm{C}$ for Southern and Northern Hemisphere mid-latitudes, and reach about $10^{\circ} \mathrm{C}$ for the North Atlantic, during winter. The cooling over tropical areas is reduced to $-1^{\circ}$ or $-2 \mathrm{C}$, with large areas of the Pacific Ocean where temperatures even increase slightly $\left(+1^{\circ}\right.$ to $\left.2^{\circ} \mathrm{C}\right)$.

Because of the Bering Strait, the difference in sea-ice extent between the LGM and the present climate is small in high latitudes for the North Pacific, but there is a huge equatorward shift of the sea-ice extent from $70^{\circ}$ to 50 latitude for the North Atlantic and Southern Hemisphere. The seasonality of the sea ice is weakened during the LGM, and the sea-ice extent is only slightly reduced during the summer season.

\section{DISCUSSION}

\subsection{Orographical impact of the ice sheet for the LGM climate}

As with most of the AGCMs' simulations of the LGM (Rind, 1987; Joussaume, 1993), the main features are reproduced in EXP2 and EXP3: shift of the storm tracks southward of the ice sheet, deepening of the North Pacific low and southward shift of the North Atlantic low, and splitting of the jet around the Laurentide ice sheet. Comparison of EXP4 and EXP1, which both have the same present SSTs and sea-ice extent, displays the impact of the orographical forcing of the ice sheets. In EXP4, there is no enhancement of the Aleutian low (not shown), thus proving that this enhancement, during the LGM, is mostly due to changes in SSTs. In contrast, the southward shift of the Atlantic low is observed in EXP2, EXP3 and EXP4; it is clearly related to the presence of the Laurentide ice sheet.

In Figure 2a (EXP4 minus EXP1), we illustrate the effect of orographical forcing on the geopotential height at $500 \mathrm{hPa}$, for the winter season. The impact of the orographical forcing is rather local, leading to anticyclonic circulation westward of the ice caps, in agreement with Held (1983) and Cook and Held (1988). These major changes in atmospheric circulation are also dependent on the size and configuration of the ice sheet, as illustrated in next paragraph.
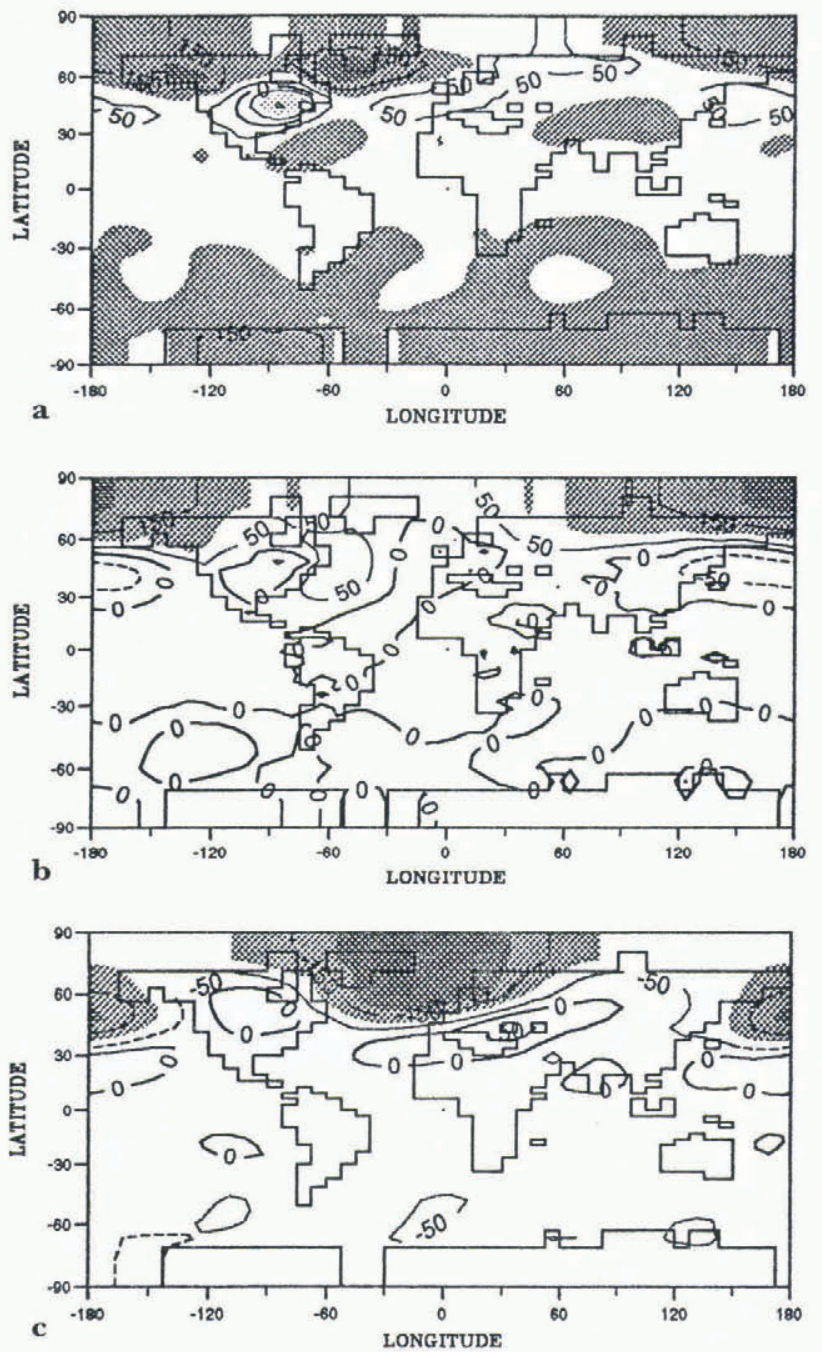

Fig. 2. Geopotential height (in m) at $500 \mathrm{hPa}$ differences for December, January and February (a) between EXP4 and EXP1, (b) between EXP2 and EXP3, and (c) between EXP2 and EXP4. In (a) and (b) dark grey is used for differences higher than $200 \mathrm{~m}$, light grey for differences higher than $100 \mathrm{~m}$; isolines are drawn for differences equal to 50 and $150 \mathrm{~m}$. In (c) dark grey is used for differences lower than $-200 \mathrm{~m}$, light grey for differences lower than $-100 \mathrm{~m}$; isolines are drawn for differences equal $10-50$ and $-150 \mathrm{~m}$.

\subsection{Sensitivity to different ice-sheet reconstructions for the LGM climate}

The comparison between EXP2 and EXP3 reveals the changes in LGM atmospheric circulation due to the differences in ice-sheet reconstructions. Although the globally and annually averaged cooling is identical for the two LGM simulations $\left(\Delta T=-3.3^{\circ} \mathrm{C}\right)$ and the geographical structure of the annual mean cooling is also very similar, there are important differences in the seasonal cycles. In Figure 3a, we depict the temperature differences between EXP2 and EXPl for the summer season. A warmer region appears clearly in EXP2 and extends southward of Fennoscandia, from the northeastern Mediterranean coast to central Russia. This warming is severely damped in EXP3, as shown in Figure $3 \mathrm{~b}$, which demonstrates that this warming is very 

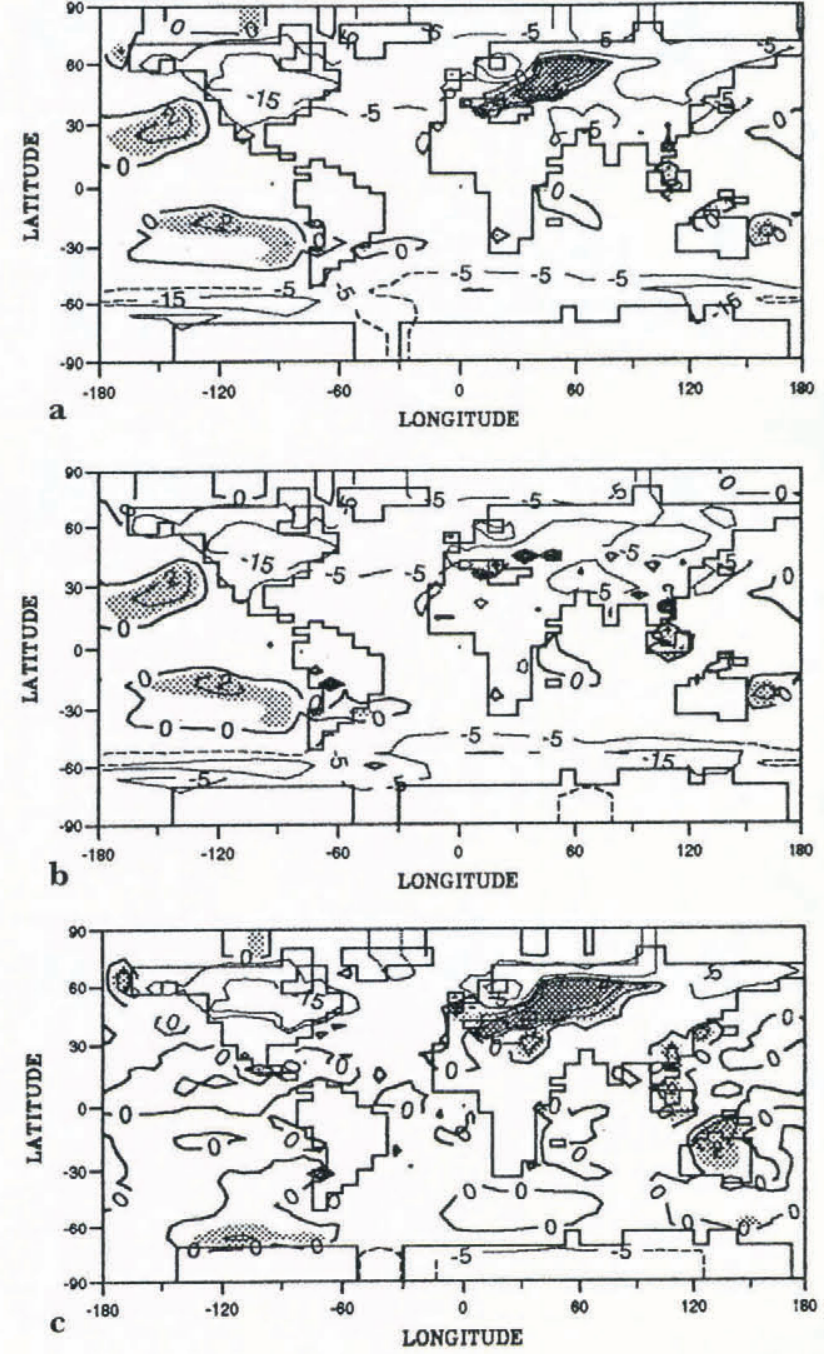

Fig. 3. Air temperature differences $\left({ }^{\circ} \mathrm{C}\right)$ for June, July and August (a) between EXP2 and EXPI, ( $b$ ) between EXP3 and EXP1, (c) between EXP4 and EXP1. Dark grey is used for temperature differences higher than $3^{\circ} \mathrm{C}$, light grey for temperature differences higher than $1^{\circ} \mathrm{C}$. Isolines are drawn for $T=2^{\circ}$ and $4^{\circ} \mathrm{C}$.

sensitive to the Fennoscandian reconstruction. This broad warmer region still exists in EXP4, as shown in Figure 3c, which proves that it is not induced by the CLIMAP SSTs. The warming obtained using the CLIMAP ISR corresponds to an increase in temperature of $+3^{\circ}$ to $5^{\circ} \mathrm{C}$, contradicting the data synthesis provided by Peterson and others (1979) and more recently by Webb and others (1993). These data are in better agreement with the results obtained with the Peltier (1994) reconstruction. In the winter season, the same phenomenon is observed over Alaska westward of the Laurentide (not shown). In both cases, the differences in temperature patterns demonstrate the impact of the ice-sheet reconstructions on the midlatitude atmospheric dynamics. We now illustrate this feature with the winter circulation.

Figure $2 \mathrm{~b}$ shows the difference of geopotential height at $500 \mathrm{hPa}$, in winter, between EXP2 and EXP3. Isocontours indicate changes in the mean flow. The warming over Alaska cannot be a direct orographical effect: there is no difference in ice-sheet elevation over Alaska between the two reconstructions. The higher elevation of the Laurentide in EXP2 intensifies the planetary waves and heat transport, leading to an increase in temperature and geopotential height. As mentioned in the previous paragraph, the higher elevation of the CLIMAP ISR induces an enhancement of the anticyclonic circulation westward of the ice sheet. The wind at $850 \mathrm{hPa}$ during winter (not shown) confirms the enhanced deepening of the Aleutian low, leading to greater transport of warmer air from the North Pacific to Alaska for CLIMAP ISR (EXP2), which explains the development of a warmer region over Alaska in winter.

Another way to illustrate the impact of ice-sheet elevation on winter atmospheric circulation for the LGM is the splitting of the jet. As Kutzbach and Wright (1985) noted, this splitting is a function of ice-cap size and distribution. In this sensitivity experiment, the ice-cap configuration modifies the structure of the splitting. We find, for the simulation using CLIMAP ice-sheet reconstruction (EXP2), the same results described by COHMAP (Anderson and others, 1988): a splitting of the jet with a northern branch at the edge of the ice cap and a southern branch on the southern part of North America (Fig. 4a). With Peltier reconstruction (EXP3), we find the same intensity but a more zonal circulation for the
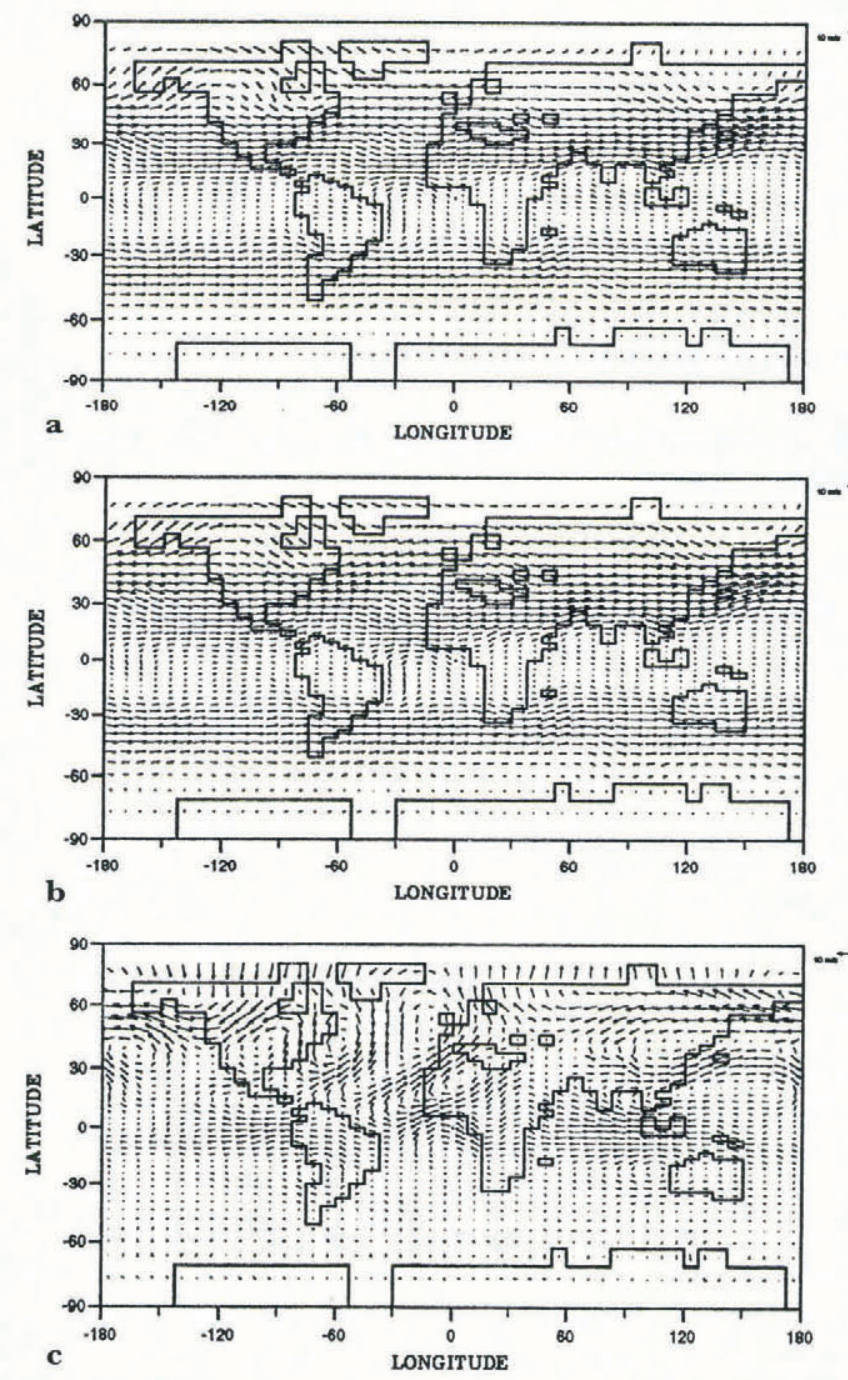

Fig. 4. a. Wind speed at $200 \mathrm{hPa}$ for EXP2 in December, January and February. b. The same for EXP3. c. Differences in wind speed between $a$ and $b$. 
northern branch of the jet (Fig. 4b). Because of the lower elevation of the Laurentide, the westerlies are strengthened over the ice cap, as shown in Figure $4 \mathrm{c}$, corresponding to the wind-speed differences between EXP2 and EXP3. The impact of the ice-sheet topography is, in our case, weaker than in Shinn and Barron's (1989) extreme-sensitivity experiment, for which they found a more defined structure of the splitting using their maximum reconstruction.

\subsection{Change in SST for the LGM}

Comparing EXP2 and EXP4, we can analyze the effect of the change of SSTs on the LGM climate. The global annually averaged cooling reaches only $1.1^{\circ} \mathrm{C}$ in EXP4, implying that the ice sheet is responsible for $33 \%$ of the global cooling during the LGM. The difference of geopotential height at $500 \mathrm{hPa}$ between EXP2 and EXP4 for the winter season, shown in Figure 2c, demonstrates the extensive thermal forcing due to the SST variations. A strong trough develops over the cold North Atlantic, covered by sea ice, as a result of the decrease of the surface heat fluxes. However, the major difference in winter sea-ice extent between the LGM and the present climate is not responsible for the southward shift of the Atlantic low which is very similar in both simulations.

\section{GONGLUSIONS}

The approach developed in this paper allows a better understanding of the orographical and thermal forcings. These sensitivity experiments show the impact of ice-sheet orography and SSTs with emphasis on the effect of different ice-sheet reconstructions on the LGM climate. We find that the temperatures simulated for Peltier reconstruction do not show the important warmer regions for the LGM that many other models found using CLIMAP (1981) reconstruction (Rind, 1987), and which contradicted to data. We also show that the deepening of the Aleutian low is due to the LGM SSTs but that the southward shift of the Atlantic low is due to the circulation induced by the Laurentide. Finally, we illustrate the different contributions of SST and ISR on the pattern of planetary waves over the Northern Hemisphere during the LGM.

\section{ACKNOWLEDGEMENTS}

We gratefully acknowledge the Laboratoire de Météorologie Dynamique (CNRS, Paris, France) for providing us with the version 4 of their GCM, Dr Peltier for providing the new ice-sheet reconstruction, M. Doutriaux (LMD) for participating in the simulations and J.Y. Peterschmitt (LMCE) for the graphic outputs.

\section{REFERENCES}

Anderson, P. M. and 32 others. Climatic changes of the last 18,000 years: observations and model simulations. Science, 241 (4869), 1043-1052.

Broccoli, A.J. and S. Manabe. 1987. The influence of continental ice, atmospheric $\mathrm{CO}_{2}$, and land albedo on the climate of the last glacial maximum. Climate Dyn., $\mathbf{1}(2), 87-99$.

Cook, K.H. and I. M. Held. 1988. Stationary waves of the ice age climate. 7. Climate., 1 8), 807-819.

Denton, G. H. and T.J. Hughes, eds. 1981. The last great ice sheets. New York, etc., John Wiley and Sons.

Held, 1. M. 1983. Stationary and quasi stationary eddies in the extratropical troposphere: theory. In Hoskins, D.J. and R. P. Pearce, eds. Large scale dynamical processes in the almosphere. London. Academic Press, 127-159.

Joussaume, S. 1993. Paleoclimatic tracers: an investigation using atmospheric general circulation model under ice age conditions 1. Desert dust. J. Geophys. Res., 98 D2), 2767-2805.

Kutzbach, J.E. and H. E. Wright. 1985. Simulation of the climate of 18,000 years BP: results for the North American/North Atlantic/ European sector and comparison with the geologic record of North America. Quat. Sci. Rev., 4(3), 147-187.

Le Treut, H. and K. Laval. 1984. The importance of cloud radiation interaction for the simulation of climate. In Berger, A. and C. Nicolis, eds. .New perspectives in climate modelling. Amsterdam, Elsevier. 199-221.

Le Treut, H. and L. Li. 1991. Sensitivity of an atmospheric general circulation model to prescribed SST changes: feedback effect associated with the simulation of cloud optical properties. Climate Dyn., 5, 171-185.

McIntyre, A. and R. Cline. eds. 1981. Seasonal reconstruction of the Earth's surface at the last glacial maximum. Boulder, CO, Geological Society of America. (Map and Chart Series MC-36.).

Peltier, R. W. 1994. Ice age paleotopography. Science, 265(5169), 195-201.

Peterson, G. M., T. Webb, III, J.E. Kutzbach, T. van der Hammen, T. A. Wijmstra and F.A. Street. 1979. The continental record of environmental conditions at 18,000 yr BP: an initial evaluation. Qual. Res., 12 (1), 47-82.

Rind, D. 1987. Components of the ice age circulation. J. Geophys. Res., 92 (D4), $4241-4281$.

Rind. D. and D. Peteet. 1985. Terrestrial conditions at the last glacial maximum and CLIMAP sea surface temperature estimates: are they consistent? Quat. Res., 24 (1), 1-22.

Sadourny, R. and K. Laval. 1984. January and July performance of the L.MD general circulation model. In Berger. A. and C. Nicolis, eds. New perspectives in climate modelling. Amsterdam, Elsevier, 173-198.

Shinn, R.A. and E.J. Barron. 1989. Climate sensitivity to continental ice sheet size and configuration. J. Am. Meteorol. Soc., 2(12), 15171537.

Webb, W., III and 7 others. 1993. Climate change during the past 18,000 years: regional syntheses, mechanisms, and causes. In Wright, H.E., Jr. ed. Global climates since the last glacial maximum. Minneapolis, MN, University of Minnesota Press, 514-536.

Webster, P.J. and N. A. Streten. 1978. Late Quaternary ice age climates of tropical Australasia: interpretations and reconstructions. Quat. Res., $10(3), 279-309$. 